\title{
Tendencias actuales de la biotecnología en Nicaragua ${ }^{1}$
}

Ian M. Roustan-Espinosa ${ }^{1}$, Fernando Quezada ${ }^{2}$ y Jorge A. Huete-Pérez ${ }^{1}$

1. Investigadores del Centro de Biología Molecular UCA. Pista Juan Pablo II. Apto. 69. Managua, Nicaragua. E-mail: huete@ns.uca. edu.ni

2. Director del Centro de Excelencia de Biotecnología de Massachussets, EEUU.

Recibido: julio 2006 / Aceptado: octubre 2006

ESTE TRABAJO ABORDA LAS TENDENCIAS DE LA INVESTIGACIÓN biotecnológica en Nicaragua. Se destaca el reciente auge de esta área del conocimiento basándose en información obtenida de los tres Congresos Nicaragüenses de Biotecnología (2002, 2004 y 2006). Se describen, en particular, las actividades y temáticas abordadas en el tercer Congreso, resaltando las ponencias más sobresalientes. Al mismo tiempo, se discute la potencialidad de este sector para la economía nacional. Esta revisión del tema, a manera de diagnóstico de la situación actual, podría contribuir a la toma de decisiones sobre el desarrollo de políticas de promoción de la investigación científica.

Palabras clave: biotecnología-Nicaragua-investigaciones / biotecnología congresos, conferencias, etc. / investigación científica

\section{Introducción}

A nivel mundial, la biotecnología representa una amplia área de disciplinas que se desarrollan a un paso acelerado, provocando tremendo impacto en la economía, la ciencia y la educación. También en Nicaragua se están desarrollando con firmeza estas ciencias: durante los últimos 10 años, se ha destacado una incipiente pero creciente comunidad científica determinada a su avance, al uso de sus aplicaciones y el mejoramiento de la educación científica en el país. Actualmente, varios grupos de investigadores y centros de investigación están ayudando a solucionar problemas concretos, principalmente en las áreas de biomedicina y biotecnología agrícola.

En un esfuerzo por impulsar estas áreas del conocimiento el Centro de Biología Molecular de la Universidad Centroamericana (UCA), ha organizado los Congresos Nicaragüenses de Biotecnología que se han convertido en una plataforma de divulgación y debate de los temas más apremiantes de la comunidad investigadora del sector biotecnológico. Este artículo es una revisión sobre los avances de la investigación científica en biotecnología teniendo como base los resultados y Memorias de los tres Congresos (2002, 2004, 2006); se abordan la historia, objetivos y alcances de estos Congresos; se describen, en particular, las actividades y temáticas abordadas en el tercero, resaltando las ponencias más sobresalientes. Al mismo tiempo, se discute la potencialidad de este sector para la 
economía nacional y las tendencias actuales más relevantes de la investigación biotecnológica del país.

\section{Historia de los Congresos Nicaragüenses de Biotecnología}

Los Congresos Nicaragüenses de Biotecnología surgieron como iniciativa del Centro de Biología Molecular de la Universidad Centroamericana en 2002. Dado el notable desarrollo de la biotecnología moderna en Nicaragua en los últimos años, y la importancia de la investigación científica para el desarrollo de una economía sólida basada en el conocimiento, se consideró necesaria la creación de un espacio para la divulgación de los trabajos que habían realizado algunos grupos de especialistas en el amplio espectro de la Biotecnología, con el propósito de promover el desarrollo y utilizar la innovación biotecnológica en Nicaragua. Dentro de estos objetivos, se ha planteado congregar, enlazar y generar sinergia entre los grupos de investigadores nacionales, a la vez que se tienden puentes de cooperación con otros sectores pertinentes (privado, público y gobierno).

Los Congresos han contado con la participación de destacados científicos de otros países, invitados por la UCA con el doble propósito de adquirir de primera mano conocimiento sobre los más recientes avances de la ciencia mundial; y fomentar colaboraciones de investigadores nacionales con extranjeros que se encuentran trabajando en áreas relacionadas. Algunos de los participantes de destacada trayectoria son Torsten Weisel (Nóbel 1983), Ricardo Miledi (Premio Príncipe de Asturias de Neurociencia), Marc van Montagú (Barón de Bélgica, miembro de la Academia de Ciencias de EEUU) y Richard Roberts (Nóbel 1993).

A la fecha se han efectuado tres Congresos nacionales, realizados cada dos años, para dar seguimiento continuo a proyectos de larga duración, y para conocer nuevas líneas de investigación. Los Congresos han sido posibles gracias al apoyo financiero del Banco Interamericano de Desarrollo, la Fundación Pew Charitable Trusts, SIDA-SAREC, Food and Agriculture Organization, Fundación New England Biolabs y fondos propios de la UCA. Además, algunas organizaciones han financiado algunas actividades parciales: CYTEDCONICYT y Ministerio del Ambiente (proyecto GEF-Biotecnología). También la Embajada de Estados Unidos en Managua ha apoyado la visita de algunos científicos estadounidenses.

El formato de los Congresos costa de cuatro grandes bloques que agrupan los principales sectores de aplicación de la biotecnología en el país: biomedicina, biotecnología agrícola, industrial y ambiental. Se incluye, además, un foro de discusión de diversos temas de importancia nacional y mundial que varía dependiendo del enfoque del evento. En estos foros se han abordado temas relacionados con bioseguridad, políticas científicas, desarrollo económico a través de ciencia y tecnología, vinculación gobierno-industria-sector académico. El tema del foro del tercer Congreso fue, precisamente, la vinculación intersectorial (3).

\section{Tercer Congreso Nicaragüense de Biotecnología}

El tercer congreso se realizó en Managua los días 20-21 de abril de 2006, con 110 participantes que representaron a diversos grupos de investigación de todo el país, incluyendo por primera vez a una representación de la Región Caribe (Universidad BICU). En el primer y segundo 
Congresos hubo 120 y 95 participantes, respectivamente. Científicos extranjeros incluyendo Brasil, Venezuela, Uruguay, Dinamarca, México y Estados Unidos formaron parte del elenco de expositores del evento. Igualmente, participaron representantes del sector gobierno (CONICYT y los ministerios de Agricultura, Finanzas, del Ambiente y Recursos Naturales y de Salud), junto con diversos empresarios y emprendedores líderes del país. Uno de los grandes logros es la creciente participación de las autoridades universitarias, en particular de la UCA, cuya participación, a su máximo nivel con la rectora Mayra L. Pérez, expresa un compromiso frente al reto de desarrollar la investigación biotecnológica. El mensaje dirigido a los congresistas por Juan Bautista Arríen, asesor de la UNESCO, representó también apoyo decidido al progreso de la investigación biotecnología y la educación científica, en general.

Biomedicina. José Felix Espinoza y Filemón Bucardo, del Departamento de Microbiología de la UNAN-León, presentaron una ponencia sobre su trabajo en rotavirus. Se trata de un estudio sobre una mutación en la posición 77 del gen VP7 de la cepa G4P[8] de rotavirus, que fue la que se determinó como la más predominante durante una epidemia de diarrea aguda en niños menores de cinco años durante febrero y marzo del 2005. El análisis filogenético del gen VP7 demostró que la cepa pertenece al linaje lc y que está distantemente relacionada con las cepas ST3 y VA70.

Jorge Huete, director del Centro de Biología Molecular de la UCA, presentó los resultados de un estudio sobre el tráfico vesicular de la más abundante cisteino proteasa (Cruzaína) en Tripanosoma cruzi, agente causal de la enfermedad de Chagas. Previamente se estableció que los efectos de inhibidores sobre el parásito eran debido a la inhibición en el procesamiento de precursores de cisteino proteasas, resultando en su acumulación en el aparato de Golgi y posterior muerte de los parásitos. En el nuevo estudio, se utilizó la técnica de yeast-twohybrid para identificar proteínas que potencialmente interactuaran con Cruzaina, con el fin de ser utilizadas como dianas moleculares de agentes quimo-terapéuticos. Igualmente, se presentaron los avances realizados en el estudio de tráfico intracelular y mecanismos de reconocimiento celular en T. Cruzi.

Los expositores Eduardo Brandt de Oliveira, de la Universidad de Sao Paulo, Brasil, y Luis Brieva, del Departamento de Bioquímica del CINVESTAV, México, abordaron métodos modernos en la síntesis de péptidos y la bioquímica estructural del metabolismo de ácidos nucleicos, respectivamente. El expositor brasileño presentó métodos de secuenciación modernos pero apropiados, para la investigación en países como los latinoamericanos, en donde la creatividad para la innovación tecnológica es un bien muy preciado. El expositor mexicano, en cambio, discutió la potencialidad y usos de métodos cristalográficos para el estudio de variados tipos de ácidos nucleicos y proteínas.

Biotecnología Agroindustrial. Con el tema de biotecnología agrícola, Edgardo Jiménez, de la Universidad Nacional Agraria (UNA), presentó un estudio sobre los efectos de transgénesis para resistencia a virus de trigo en las interacciones de planta-vector-virus. Se presentaron datos sobre los efectos de los transgenes en la longevidad, comportamiento y eficiencia de transmisión viral del áfido $R$. Padi. Guillermo Reyes, también de la UNA, presentó resultados de un estudio sobre cocoyam (Xanthosoma spp.) en Nicaragua, 
haciendo énfasis en el Virus del Mosaico Dasheen (Dasheen Mosaic Virus). Representando a la prestigiosa Pennsylvania State University, Mark Guiltinan presentó datos sobre el trabajo que realizan en el mapa genético del Cacao, además del desarrollo de plataformas en PCR de tiempo real y microarreglos para el estudio de la expresión génica en de esta especie. Por otra parte, Carolina Vega, de la UNA, presentó avances de varios proyectos del área de cultivo de tejidos.

Otras aplicaciones biotecnológicas. En la última sesión de presentaciones científicas, bajo el tema de Aplicaciones Biotecnológicas, Eduardo Flores realizó un resumen de las investigaciones realizadas por el Centro de Investigaciones de Ecosistemas Acuáticos (CIDEA) de la UCA. Se presentaron datos de estudios nacionales para determinar la prevalencia de múltiples virus (WSSV, TSV, YHV e IHHNV) en camarones silvestres de Nicaragua y Panamá, al igual que diversos vínculos y beneficios mutuos obtenidos con la industria privada. El tema de biorremediación, enfocado en la degradación de toxafeno en medio líquido, fue tratado en la presentación de Martha Lacayo del Centro de Investigaciones para los Recursos Acuáticos (CIRA) de la UNAN-Managua. En el estudio, se ensayaron diversos sustratos y variables para obtener las condiciones óptimas para la degradación del plaguicida toxafeno utilizando hongos producidos por la descomposición de la madera (Bjerkandera spp. BOL13).

Universidad-Empresa. Es sabido que las economías de países como China, India y Corea se encuentran en continuo ascenso. Estos tres países han adoptado y apoyado el desarrollo en ciencias biológicas modernas como la biotecnología y han sabido acoplar los avances realizados en investigación con sus aplicaciones en el sector industrial. Para generar este repunte económico, se han establecido diálogos y nexos entre el sector académico y el industrial. Considerando lo anterior, la temática central del Foro del tercer Congreso fue la vinculación entre el sector privado y el sector académico. En una sesión adicional, se desarrolló el tema de colaboración Universidad-Industria para el desarrollo de la biotecnología a cargo de Fernando Quezada, director ejecutivo del Centro de excelencia en Biotecnología de Massachussets, Estados Unidos.

Fernando Quezada se refirió a la necesidad que presenta Latinoamérica de establecer efectivas relaciones de trabajo entre los sectores académicos (instituciones de investigación) y las industrias tradicionales, para obtener mayor competitividad por parte de la empresa privada en el mercado mundial (globalización) y para satisfacer las crecientes demandas de los diversos tratados de libre comercio. Igualmente, se trataron los beneficios que pueden ser obtenidos mediante estas vinculaciones en el sector académico. Ejemplos de vinculaciones en Estados Unidos, Europa y Latinoamérica fueron presentados, además de múltiples factores que contribuyen con el éxito de este tipo de esfuerzos. La participación de empresarios como Ricardo Terán fue de singular importancia para alimentar la discusión desde la perspectiva empresarial y del sector privado.

Simposio sobre los retos de la biotecnología en Nicaragua. Niels Thygesen, de la Technical University of Denmark, presentó un modelo de un plan de desarrollo de la biotecnología en Nicaragua. Abordó los factores y acciones necesarios para generar un plan nacional, contemplando los recursos humanos y financieros, así como equipamiento, proyectos y 
actividades específicas. Esta ponencia sirvió de introducción a la discusión del simposio. Por su parte, los panelistas tuvieron la tarea de debatir el tema de retos y perspectivas de la biotecnología en Nicaragua.

El panel estuvo integrado por representantes de los sectores académico y gubernamental: Jorge Huete, director del Centro de Biología Molecular de la UCA; Aldo Roja, del Instituto Nicaragüense de Tecnología Agropecuaria (INTA); Ernesto Medina, antiguo Rector de la UNAN-León; y Fernando Quezada, expositor del extranjero, quien también actuó como moderador del simposio.

Los panelistas ofrecieron sus puntos de vista sobre las áreas que representan grandes retos para los sectores productivos del país y el papel de las tecnologías emergentes para aportar soluciones. Los miembros del panel concordaron en la necesidad de un diálogo continuo entre todos los sectores y actores relevantes al tema, haciendo énfasis en la comunidad agrícola. Hubo coincidencia en cuanto a la importancia de unir fuerzas (crear alianzas) y la urgencia de organizar un plan nacional. Fue generalizado el sentimiento de crear un comité o comisión de trabajo encargada del desarrollo a largo plazo de la biotecnología en Nicaragua, identificando fortalezas y debilidades, además de definir prioridades. Se reconoció que el apoyo a la investigación básica aumentará la excelencia y competitividad de la comunidad científica nicaragüense. En el área de ciencia aplicada, se propusieron múltiples temas para estimular las aplicaciones científicas con relevancia industrial y comercial.

Después de los comentarios de los panelistas, la audiencia participó activamente en la discusión de diversos aspectos que fueron percibidos como prioritarios para Nicaragua. Parte de la audiencia expresó la necesidad de ampliar la definición de biotecnología para incluir todos los aspectos de metodologías biológicas modernas para un mejor estudio de los recursos naturales en agricultura y salud humana y animal. Otra parte mencionó la carencia de una base de datos de recursos humanos, dada la importancia de esta área como un factor en el éxito de la construcción de una plataforma biotecnológica viable. La participación de la comunidad rural (sector campesino) será fundamental en este proceso. Se señaló que las instituciones universitarias en Nicaragua están en la mejor posición para tomar iniciativas de colaboración con los sectores privado y gubernamental. Se recomendó la selección de ciertos nichos y áreas de relevancia. Las áreas de investigación de especial interés incluyen acuacultura, conservación de recursos naturales y mejoramiento de cosechas, entre otras. La formulación de una legislación adecuada y un marco regulatorio será de particular importancia para sentar las bases que aceleren el desarrollo de la biotecnología agrícola. Varios miembros mencionaron que se deben estudiar con especial atención las experiencias de otros países como México, en cuanto al modelo de desarrollo biotecnológico.

\section{Tendencias y perspectivas de la biotecnología en Nicaragua}

Durante la última década, el avance experimentado en biotecnología a nivel mundial ha sido intenso. Los ejemplos van desde el arroz dorado, organismo genéticamente modificado con mayor cantidad de beta-caroteno (provitamina A); pasando por la secuenciación de genomas incluyendo al humano, chimpancé, y varias plantas modelo; hasta llegar al desarrollo de nuevas tecnologías de secuenciación automática, PCR de tiempo real y los microarreglos. 
En Nicaragua, durante el mismo período, se han experimentado avances en el desarrollo de ciencia y tecnología, principalmente en las áreas biomédicas y de biotecnología agrícola. La fundación del Centro de Biología Molecular de la UCA en 1999 y del Laboratorio de Biología Molecular de la UNA tres años después, son claro ejemplo del enorme interés suscitado en las universidades principales del país. Se ha calculado que existen unas 150-200 personas ligadas al tema de la Biotecnología, de los cuales entre 25-30 son investigadores de las universidades. El presupuesto anual de estos grupos oscila entre 20-50 mil dólares. Lamentablemente, estas iniciativas son apenas esfuerzos aislados surgidos por iniciativa de investigadores entusiastas, pero que carecen del respaldo financiero continuo del gobierno o la empresa privada.

Nichos propicios. Múltiples estudios se han realizado para la caracterización molecular de patógenos tanto de humanos y de importantes cultivos, el desarrollo de métodos moleculares de diagnóstico para enfermedades infecciosas, el uso de marcadores moleculares para identificación humana y su extensión al uso de marcadores para enfermedades hereditarias. En el Cuadro 1 se presenta un muestrario de las líneas de investigación actualmente en desarrollo.

Uno de los sectores de investigación que demanda más desarrollo, dada la base agrícola en que descansa la economía nicaragüense, es la biotecnología agrícola, que incluye la biotecnología de cultivos importantes para la agricultura local. Una meta urgente consiste en desarrollar capacidades de infraestructura y facilitar la transferencia tecnológica y la capacitación de recursos humanos. Dados los problemas serios de plagas y limitantes en la productividad agrícola nacional podrían visualizarse algunos programas de mejoramiento por transgénesis. Los OGMs han demostrado en países como India, China y Brasil todo su potencial para simplificar su manejo y para aumentar significativamente las ganancias económicas, no únicamente del sector privado que los comercializa, sino también de los productores y consumidores. Es importante recalcar que es necesario el desarrollo de estas líneas de investigaciones in situ para la producción de eventos que reúnan las características necesarias para satisfacer las necesidades internas del país. Conociendo nuestros problemas, nuestros especialistas deberían acceder a estas tecnologías para plantear soluciones apropiadas a nuestra realidad. Por otra parte, la selección asistida por marcadores moleculares puede ser implementada para mejorar ciertos rasgos de interés agroindustrial en cultivos vegetales y en animales.

Dentro del área de biotecnología ambiental, ya se están dando los pasos necesarios para el desarrollo de técnicas de bioremediación, la utilización de plantas, bacterias, hongos u otros organismos vivos para la limpieza de ambientes contaminados. Esta es otra área que, sin duda, tendrá un desarrollo acelerado durante las próximas décadas.

Otras dos líneas de investigación interesantes, dada la gran biodiversidad con que cuenta el país, son la bioprospección de compuestos de interés industrial y médico, y la caracterización de la biodiversidad usando técnicas moleculares. La identificación de especies de insectos, plantas y/o animales endógenos de Nicaragua o la región pueden conllevar por interés comercial, académico o de conservación, al desarrollo de iniciativas para la secuenciación de genomas específicos, para su utilización. 
El desarrollo de infraestructura de investigación en la región para la secuenciación de genomas de importancia nacional o regional conllevará al desarrollo de otro grupo de áreas de investigación que serán fundamentales para el avance de ciencia en Nicaragua. Tanto la Genómica, con todas sus denominaciones: funcional, comparativa, evolutiva, computacional, así como la proteómica y la bioinformática tendrán gran oportunidad desarrollo, siendo esta última la de más fácil acceso a la comunidad científica nacional debido a que no se necesita mucha inversión para su desarrollo, puesto que todos los procesos son realizados in sílico. Además, hay que considerar que una ventaja adicional es que se cuenta ya con un buen número de jóvenes expertos en informática y no costaría mucho entrenarlos en bioinformática.

Transferencia Tecnológica y Comercialización. Es importante hacer énfasis en que el desarrollo de la transferencia de tecnologías y aplicaciones de la ciencia tienen que ir a la par del desarrollo de la investigación y ciencia básica. La generación de conocimiento y el estudio meramente académico, aunque no genera dividendos a corto plazo, es sumamente necesaria para fomentar la creación de una base científica sólida y para que, a largo plazo, la ciencia nicaragüense se transforme de receptora en transmisora y generadora de información y tecnologías. Las áreas básicas de genética, biología del desarrollo y biomedicina deberán ser priorizadas y su avance se verá acelerado cuando se tenga identificado un número selecto de organismos modelo propios del país o la región. Tal es el caso del maíz, cuyo genoma lo han venido trabajando, en parte, grupos norteamericanos y mexicanos.

Un área que dará inicio cuando se establezca la base en ciertas áreas de investigación y ciencia será la de "bioemprendedurismo". Surgirán investigadores que, a través de sus proyectos, pueden iniciar independientemente, o formando alianzas estratégicas con profesionales de otras áreas, el desarrollo de empresas biotecnológicas. A la fecha no existen empresas que realicen investigación en biotecnología. Estas empresas proveerían no solamente de empleos, sino también aumentarían el nivel económico del país y la región. En países desarrollados, el capital de negocio generado por las empresas biotecnológicas es multimillonario.

A la par del desarrollo investigativo y empresarial, el desarrollo de una educación científica en todos sus niveles tiene que ser consolidado. La introducción temprana de ciencia, sus aplicaciones y avances, dentro del currículo en las escuelas primarias y secundarias debe de ser una prioridad. A nivel de universidades, tiene que irse gestando el desarrollo de programas nacionales de postgrados, maestrías y doctorados.

Coordinación y Liderazgo. Hace falta una cohesión de los grupos de investigadores y, más que crear nuevos grupos e institutos, convendría concentrar esfuerzos en la consolidación de los ya existentes. La planeación de nuevos proyectos con fondos de la cooperación internacional debería tomar en cuenta la participación de varios grupos a la vez de integrar a los productores y beneficiarios. Para el desarrollo de todas estas áreas y líneas de investigación, es necesario un trabajo organizado y sinérgico entre los miembros de la comunidad científica nacional.

Dando un paso para la creación de estas condiciones, un grupo de científicos tuvieron la 
iniciativa de crear la Sociedad Científica Nicaragüense (4), que se convirtió en un núcleo de conexión de los científicos nacionales y extranjeros interesados en el avance de la ciencia nicaragüense. Esta organización independiente y sin fines de lucro promoverá el desarrollo de la investigación y la educación científica en el país (5). Mediante iniciativas como ésta, se pretende crear una plataforma para la optimización de los recursos presentes en el país, a la vez que se busca promover el diálogo entre todos los sectores que son partes fundamentales para mejorar el estado de la ciencia, causando un impacto positivo en el estado socio-económico de Nicaragua. Al organizar al gremio de científicos, se podrá elaborar una agenda (plan estratégico nacional) en ciencia y tecnología con subprogramas en sectores prioritarios como el de biotecnología.

\section{La participación multidisciplinaria e intersectorial será de fundamental importancia.}

El triángulo de vinculación y alianzas entre el sector privado, el sector gobierno y el sector académico es clave para el desarrollo de la investigación y la educación científica, al igual que para el desarrollo de una agenda nacional en dichas áreas. Eventos como los Congresos Nicaragüenses de Biotecnología representan un espacio propicio para el debate sobre las políticas y estrategias de desarrollo sectorial. Mientras más divulgación del quehacer científico, tanto al público en general como a los sectores privado y gobierno haya, más clara será la visión de la necesidad profunda que tiene la sociedad nicaragüense del auge en ciencia y tecnología. Asimismo, esto contribuiría a una mejor comprensión del público y facilitaría la participación ciudadana en el debate sobre diversas temáticas.

Ha sido un consenso de la comunidad interesada en la biotecnología que, para que este sector pueda tener un impacto duradero, hace falta trazar políticas científicas respecto al tema de la biotecnología, que promuevan la superación del recurso humano existente; políticas de estímulo y soporte, con fondos competitivos para el avance de investigaciones de alta prioridad e interés nacional; políticas que permitan la creación de oficinas que promuevan la educación continua de científicos jóvenes. Estos jóvenes formarían una necesaria masa crítica de pensadores que podrían llegar a concretar metas cada vez mayores y promoverían la consolidación de la ciencia Nicaragüense.

En el Cuadro 2 se resumen algunas de las principales necesidades y limitaciones que actualmente afronta el sector biotecnológico del país. Un plan nacional de biotecnología como el planteado por los asistentes del tercer Congreso deberá transformar estas dificultades en metas y objetivos prácticos. El que estas metas lleguen a ser realidad es responsabilidad de múltiples sectores y de la capacidad de integración que éstos generen. Las tendencias de la biotecnología en Nicaragua, según se desprende de los trabajos de los investigadores nacionales aquí discutidos, apuntan hacia un posible impacto sólido en lo económico y social, en la investigación básica y la educación científica. La loable tarea de estos grupos de investigación es digna de ser estimulada • 


\section{Agradecimientos}

El Centro de Biología Molecular de la UCA agradece el apoyo continuo de la Fundación y compañía New England Biolabs, Inc. Especial agradecimiento a Regina Lacayo del PAITMIFIC y Silvia Montano de la Fundación Pew Charitable Trusts.

\section{Notas}

1 Este artículo está basado en las Memorias de los tres Congresos Nicaragüenses de Biotecnología.

\section{Referencias bibliogràficas}

-Memorias del Primer Congreso Nicaragüense de Biotecnología, UCA (2002)

-Memorias del Segundo Congreso Nicaragüense de Biotecnología, UCA (2004)

-Memorias del Tercer Congreso Nicaragüense de Biotecnología, UCA (2006)

-HUETE-PÉREZ, J. A., (2006). "New scientific society in Nicaragua". Science, Jun 2; 312 (5778)

-HUETE-PÉREZ, J. A. \& OROZCO-GONZÁLEZ, D. (2001). “Percepciones sobre biotecnología en Nicaragua". Encuentro 58: 83-90. 


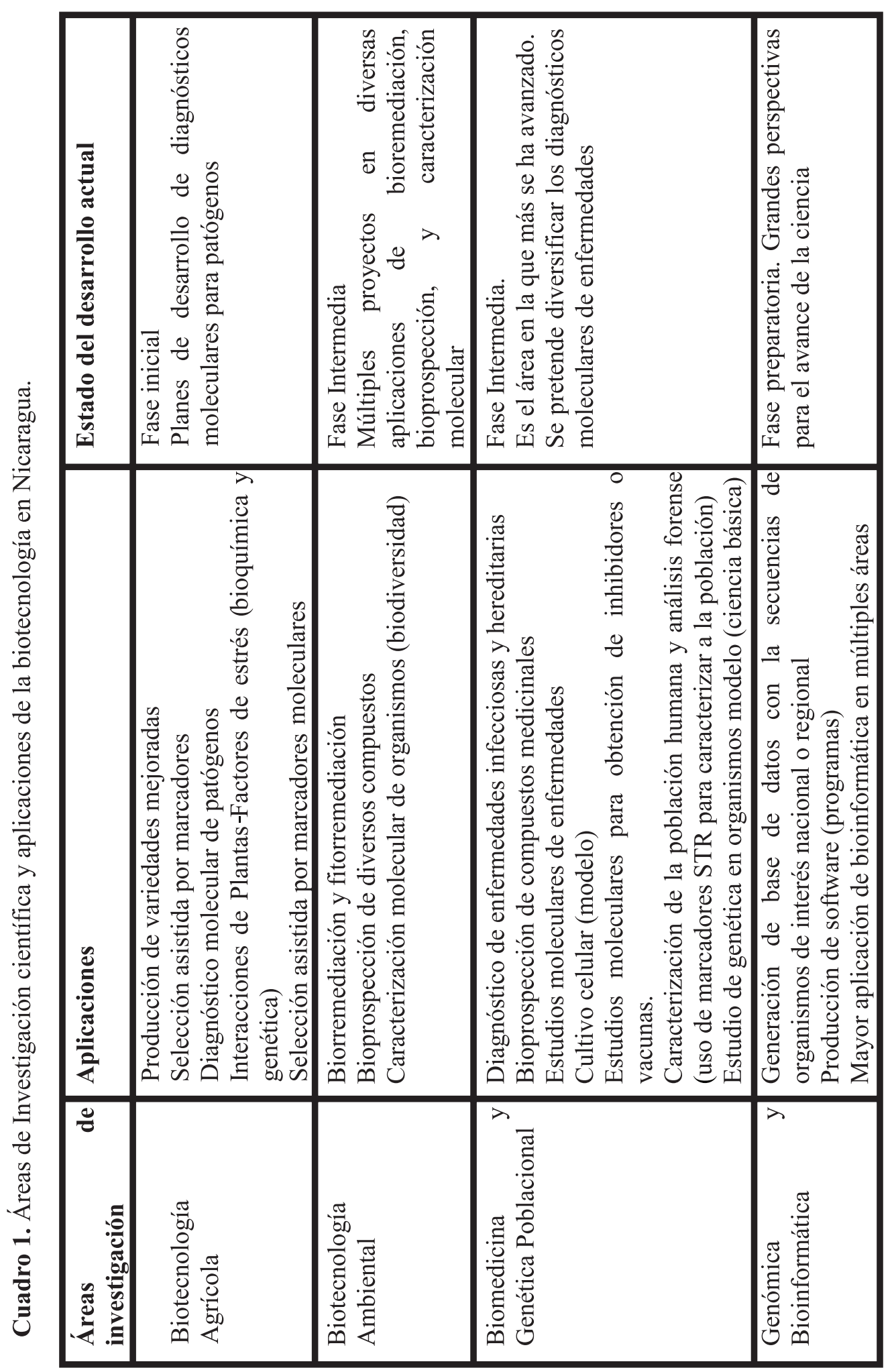



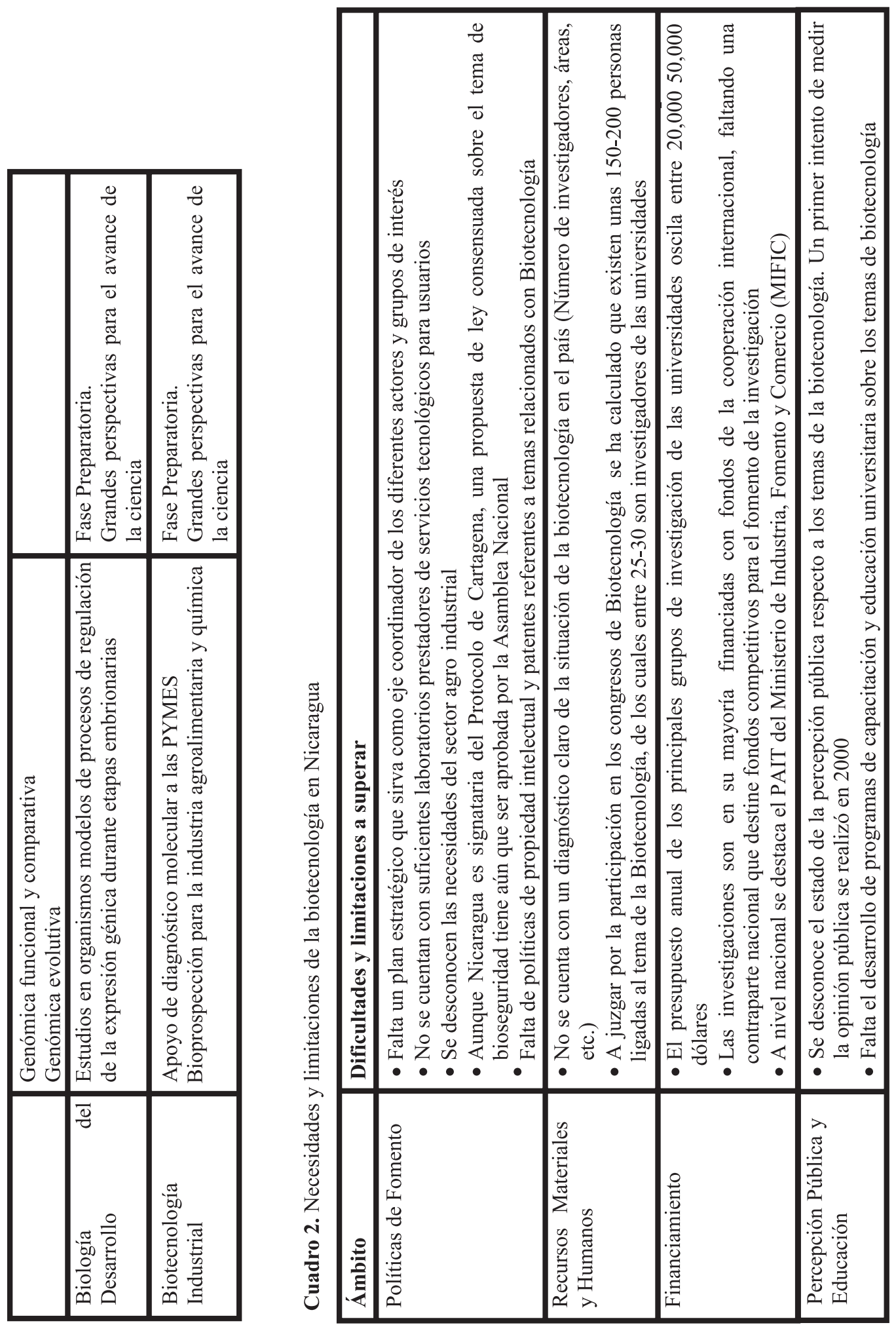